\title{
Comparative Performance and Barrier Properties of Biodegradable Thermoplastics AND NANOBIOCOMPOSITES versus PET for Food Packaging ApPLICATIONS*
}

\section{Cava, ${ }^{1}$ E. Giménez, ${ }^{2,3}$ R. Gavara ${ }^{1}$ and J. M. Lagaron ${ }^{1,3 \dagger}$}

${ }^{1}$ Institute of Agrochemistry and Food Technology (IATA) CSIC, Apdo. Correos 73, Burjassot 46100, Spain

${ }^{2}$ Department of Technology, Area of Materials University Jaime I, Castellon, Spain

${ }^{3}$ Nanobiomatters Ltd., CEEI, Av. Benjamin Franklin 12 46980 Paterna (Valencia), Spain

\begin{abstract}
This article reports on preliminary studies of several comparative packaging properties between polyethylene terephthalate (PET) packaging films and biodegradable biopolymers such as polycarpolactone (PCL), polylacticacid (PLA), amorphous PLA (aPLA), and polyhydroxyalcanoates copolymer with $8 \mathrm{~mol} \%$ valeriate (PHBV) and of some nanobiocomposites, in terms of thermal and retorting resistance (thermal humid processes) and oxygen, water vapor, aroma, and solvent barrier by means of time-resolved synchrotron radiation, FT-IR and direct permeation methods. This work suggests that while PHBV can easily withstand retorting and shows excellent water and aroma (limonene and linalool) barriers compared with PET, its solvent resistance (toluene and ethanol) and oxygen barrier properties are poorer. First trials with compression molded food contact complying nanobiocomposites of PCL and aPLA show enhanced oxygen barrier but not sufficient, as yet, to outperform high-oxygen-barrier grades of PET film.
\end{abstract}

KEY WORDS: biodegradable, nanobiocomposites, PCL, PLA, PHBV, PET, packaging films, oxygen permeability, WVTR, diffusion, ethanol, toluene, limonene, linalool, FT-IR, DSC.

*This is an expansion of a paper presented at the Society of Plastics Engineers' ANTEC 2005 conference held in Boston, Massachusetts on May 1-5, 2005. Copyright SPE.

${ }^{\dagger}$ Author to whom correspondence should be addressed. E-mail: lagaron@iata.csic.es

Journal of PLASTIC FILM \& SHEETING, Vol. 00-Month 200?

8756-0879/0?/00 0001-10 \$10.00/0 DOI: 10.1177/875608790?071354

(C) 200? SAGE Publications 


\section{INTRODUCTION}

D IODEGRADABLE PLASTICS ARE materials that present a number Oof excellent and promising properties for a number of applications, including packaging, automotive, and biomedical applications. Besides the inherent and important sustainability and/or biodegradability of these materials, there are other important properties like transparency (some proteins and polysaccharides) and excellent film-forming properties via casting for coatings. Moreover, thermoplastic biopolymers such as polylactic acid (PLA), polycaprolactone (PCL), polyhydroxyalcanoates (PHB), and the PHB copolymer with $8 \mathrm{~mol} \%$ valeriate (PHBV) present good thermal, permselective, mechanical, and processability properties $[1,2]$. However, in general terms, biodegradable materials are either strongly plasticized by sorption of moisture or have, for instance, only medium barrier properties to gases, vapors, or hydrocarbons. It is, therefore, of industrial interest to increase the overall performance of these materials in order to generate 'added value' arguments to counteract negative issues such as current pricing to enable their substitution for more well-established oil-based materials. In this context, functional nanoadditives, such as nanoclays with tailor-made and eco-harmless modifications, have a significant potential to enhance mechanical and barrier properties of these materials and provide controlled release of functional (antimicrobial, antioxidant, bioactives, etc.) substances [3]. In the present study, the performance of amorphous PLA (aPLA), PLA, PCL, PHBV, and some of their nanocomposites is compared to that of polyethylene terephthalate (PET).

\section{EXPERIMENTAL PROCEDURE}

The materials were thermally treated at $120^{\circ} \mathrm{C}$ during $20 \mathrm{~min}$ in the presence of water in an autoclave (retorting process) and under dry conditions in an oven (annealing process). The proprietary modified clays, used for melt blending of nanocomposites, were provided by NanoBioMatters S.L., Spain. Amorphous poly(lactic acid) containing $12 \mathrm{~mol} \%$ of D-lactide was supplied by Galactic (Belgium), and semi-crystalline PLA was supplied by Natureworks (US). PCL was supplied by Solvay (Belgium) and PHBV ( $8 \mathrm{~mol} \%$ of valeriate) was purchased from Goodfellow, UK, as $70 \mu \mathrm{m}$ extruded film. A PET packaging film (characterized by FT-IR and DSC) supplied by Neoplastica S.A. (Porriño, Spain) of about $28 \mu \mathrm{m}$ thickness was used throughout the experiments $\left(\Delta H_{\text {melting }}-\Delta H_{\text {coldcryst }}=11 \mathrm{~J} / \mathrm{g}\right.$, 
$T_{\mathrm{m}}=252^{\circ} \mathrm{C}$, and $T_{\text {coldcryst }}=125^{\circ} \mathrm{C}$ ). PET2, another PET packaging film (also characterized by FTIR and DSC) of $15 \mu \mathrm{m}$ thickness with higher crystallinity and melting point $\left(\Delta H_{\text {melting }}=34 \mathrm{~J} / \mathrm{g}, T_{\mathrm{m}}=260^{\circ} \mathrm{C}\right)$, was only tested for limonene permeability. Transmission FT-IR experiments were recorded under an $\mathrm{N}_{2}$ purged environment using a Bruker Tensor 37 equipment with $4 \mathrm{~cm}^{-1}$ resolution during desorption of limonene, linalool, ethanol, methanol, toluene, and water from saturated - by immersion in the media - specimens of PHBV and semi-crystalline PLA materials. Further details about the preparation of the FT-IR experiments can be found in [4].

Direct permeability to water, aroma, and solvent components was measured during weight loss experiments using aluminium cells developed at our laboratories at $21^{\circ} \mathrm{C}$ and $40 \% \mathrm{RH}$ [5]. Films were sandwiched between the aluminium top (open O-ring) and bottom (deposit for the permeants) parts of the cell with pressure maintained by screws. A rubber O-ring was placed between the film and the bottom part of the cell to enhance sealability. Then the bottom part of the cell was filled with the permeant and the pinhole secured with a rubber O-ring and a screw. Finally, the cell was placed in the desired environment and the solvent weight loss through the film was monitored and plotted as a function of time. Cells with aluminium films were used as control samples to estimate solvent loss through the sealing. Cells clamping polymer films but with no solvent were used as blank samples to monitor water uptake. Solvent permeation rates were estimated from the steady-state permeation slopes. Hydrocarbon loss was calculated as the total cell loss minus the loss through the sealing and plus the water weight gain.

DSC experiments were carried out at $10^{\circ} \mathrm{C} / \mathrm{min}$ in a Perkin Elmer DSC7e. Time-resolved WAXS experiments were carried out during temperature scans with the soft condensed matter synchrotron beam at HASYLAB (DESY) in Hamburg (Germany). Scattering patterns were recorded using a one-dimensional detector and an incident radiation wavelength, $\lambda$, of $0.15 \mathrm{~nm}$. WAXS data were corrected for detector response and beam intensity. The humid temperature scans (heating from 25 to $120^{\circ} \mathrm{C}$ at $5^{\circ} \mathrm{C} / \mathrm{min}$, isotherm at $120^{\circ} \mathrm{C}$ for $20 \mathrm{~min}$ and cooling back to $25^{\circ} \mathrm{C}$ at $10^{\circ} \mathrm{C} / \mathrm{min}$ ) were performed in the presence of water. To do so, the sample was sealed in the presence of water between aluminium films and O-ring rubber seals inside typical screwed rectangular cell compartments, which were designed for measuring liquids as a function of temperature [6]. Experiment success was checked by observation of constant background intensity over the experiment and presence of moisture in the cell 

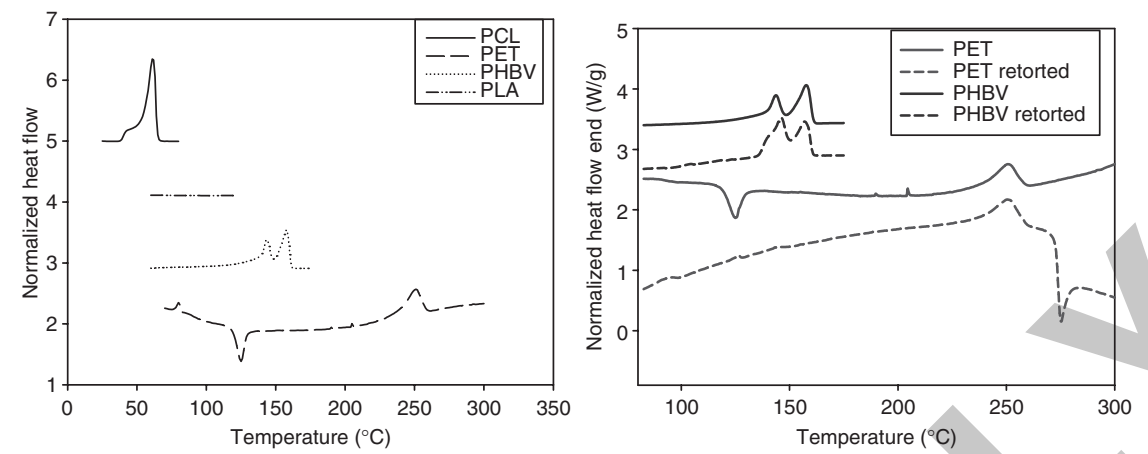

Figure 1. Melting endotherms (left) of all materials and melting endotherms (right) of PET and PHBV before and after retorting.

after termination of the thermal experiments, which indicated that moisture did not leak from the cell during the temperature run. These experiments are thought to closely simulate circumstances occurring during industrial retorting processes.

The oxygen transmission rate through vacuum-dried extruded specimens was measured using an Oxtran 2/20 instrument (Modern Control Inc., Minneapolis, MN, USA).

\section{RESULTS}

Figure 1 shows the melting endotherms of the materials from room temperature to $350^{\circ} \mathrm{C}$. This figure clearly shows that only PET and PHBV have melting features above $120^{\circ} \mathrm{C}$, i.e., the temperature commonly used during retorting of packaged food materials. aPLA is amorphous and PCL melts around $60^{\circ} \mathrm{C}$. From Figure 1, it can also be seen that the PET food-packaging extruded film (highly amorphous with $28 \mu \mathrm{m}$ thickness) shows an exotherm before melting typical of the cold crystallization exhibited by the polymer.

PHBV and PET specimens were also analyzed after retorting (Figure 1). From the experiments it is clear that PET undergoes crystallization during the retorting experiment because the cold crystallization exotherm is no longer observed in the retorted specimen. This observation was further supported by synchrotron combined WAXS and SAXS experiments and by calorimetric methods during retorting in situ inside steel pans (results not shown). 


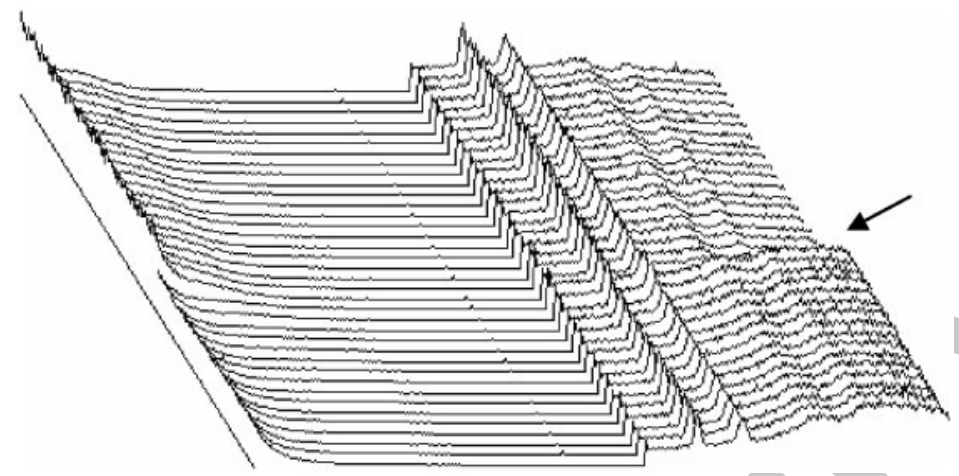

Figure 2. Simultaneous SAXS and WAXS experiments of PHBV during in situ retorting, i.e., heating the sample to $120^{\circ} \mathrm{C}$ (arrow) and thermal treatment during $20 \mathrm{~min}$ at $120^{\circ} \mathrm{C}$ in the presence of water.

Figure 2 shows the synchrotron simultaneous SAXS and WAXS experiments during in situ retorting of PHBV. From the results, it is clear that this polymer withstands the treatment fairly well, without apparent damage of the crystalline structure. Significant crystallinity deterioration has been previously observed in ethylene-vinyl alcohol copolymers (EVOH) [6,7].

Figure 3 gathers diffusion data as determined by FT-IR spectroscopy during typical desorption experiments of limonene, toluene, methanol, ethanol, linalool, and water from saturated PHBV specimens and compares this to diffusion of water in semi-crystalline PLA. Semi-crystalline PLA has been previously studied for its oxygen permeability [8] and compared to PET, and has also been studied to determine ethyl acetate and D-limonene transport properties [9]. It is remarkable to note that the spectroscopic technique is able to easily determine diffusion coefficients of the penetrants even when sorption levels by conventional weight uptake cannot be unambiguously discerned, i.e., water and limonene sorption in PLA are not easy to determine by gravimetry [9]. Thus, from Figure 3, it is proven again that the determination of diffusion coefficients of aroma components is possible in simple FT-IR transmission experiments as previously reported [4]. Diffusion coefficient goes from faster to slower in the order water $>$ methanol $>$ ethanol $>$ toluene $>$ linalool $>$ limonene for PHBV.

Table 1 gathers limonene diffusion data as measured by FT-IR and limonene uptake data as determined by gravimetry in PHBV and PCL. Table 1 also shows direct permeability data for limonene, linalool, 


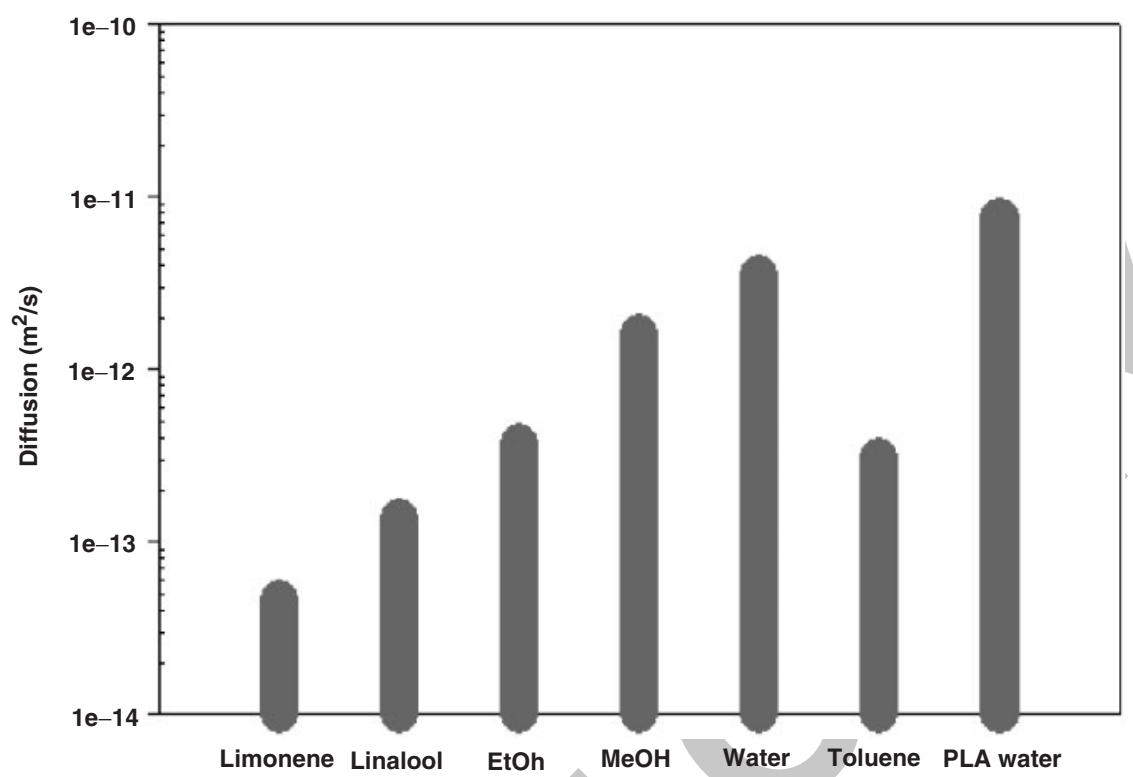

Figure 3. Diffusion coefficient of some compounds in PHBV as determined by FT-IR and compared to water diffusion in semi-crystalline PLA.

Table 1. Diffusion, uptake, and permeability data for PHBV, PET, and PCL.

\begin{tabular}{llcc}
\hline & PHBV & PET & PCL \\
\hline FT-IR limonene D value $\left(\mathrm{m}^{2} / \mathrm{s}\right)$ & $5.0 \times 10^{-14}$ & $4.0 \times 10^{-13}$ & $5.5 \times 10^{-13}$ \\
\% limonene weight uptake $\left(\mathrm{W} / \mathrm{W}_{\text {dry }}\right)$ & 1 & - & 30 (after $800 \mathrm{~h})$ \\
Limonene $\mathrm{P}$ value $\left(\mathrm{g} / \mathrm{s} \mathrm{m}^{2} \mathrm{~Pa}\right)$ & $2.8 \times 10^{-11}$ & $1.8 \times 10^{-10}$ & - \\
Linalool $\mathrm{P}$ value $\left(\mathrm{g} / \mathrm{s} \mathrm{m}^{2} \mathrm{~Pa}\right)$ & $1.6 \times 10^{-10}$ & $3.5 \times 10^{-10}$ & - \\
Toluene $\mathrm{P}$ value $\left(\mathrm{g} / \mathrm{s} \mathrm{m}^{2} \mathrm{~Pa}\right)$ & $1.4 \times 10^{-10}$ & $6.2 \times 10^{-12}$ & - \\
Ethanol $\mathrm{P}$ value $\left(\mathrm{g} / \mathrm{s} \mathrm{m}^{2} \mathrm{~Pa}\right)$ & $1.0 \times 10^{-11}$ & $1.5 \times 10^{-13}$ & - \\
Water $\mathrm{P}$ value $\left(\mathrm{g} / \mathrm{s} \mathrm{m}^{2} \mathrm{~Pa}\right)$ & $3.0 \times 10^{-12}$ & $5.5 \times 10^{-12}$ & - \\
\hline
\end{tabular}

toluene, ethanol, and water vapor in PHBV and PET. Limonene uptake is seen to be very high for PCL and much lower for PHBV. The sorption of limonene in PCL never reaches equilibrium as sorption slowly continues well beyond the initial fast rise regime in the sorption curve versus time. Direct permeability for PHBV goes from higher to lower in the order linalool $>$ toluene $>$ limonene $>$ ethanol $>$ water and for PET in the order linalool $>$ limonene $>$ toluene $>$ water $>$ ethanol. From Table 1, it can also be seen that the permeability to water and linalool does not strongly differ between PHBV and PET, being slightly higher for the latter. 


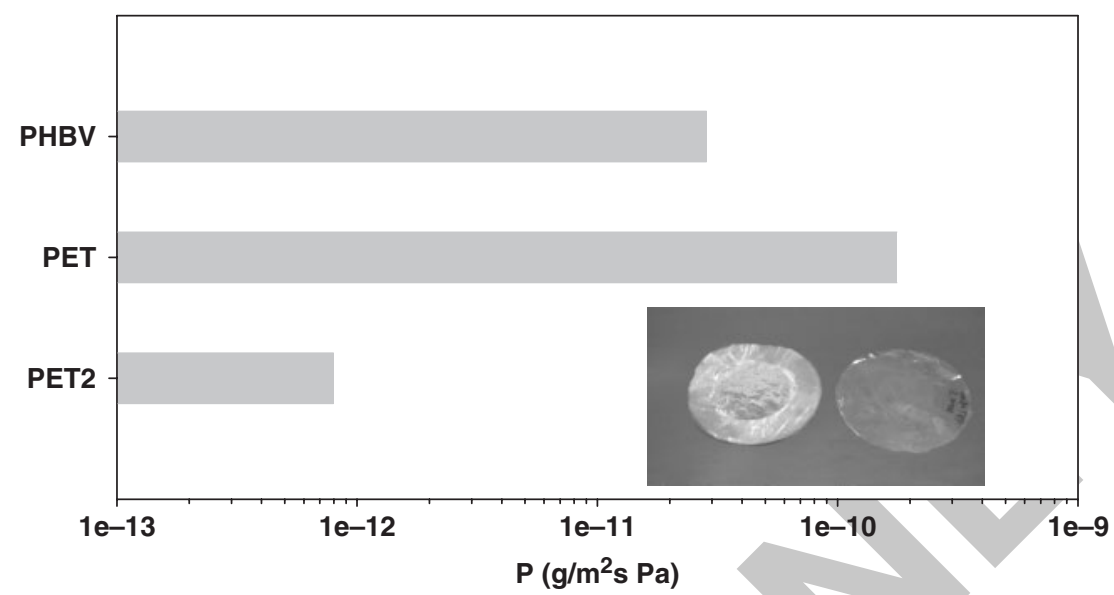

Figure 4. Limonene permeability of two different PET films and a compression-moulded film of PHBV. The inset picture shows the two PET films (the more crystalline and higher melting point PET2 film is depicted on the right hand side) after limonene testing at $21^{\circ} \mathrm{C}$.

Permeability to limonene is clearly higher for PET than for PHBV; the PET film is seen to be strongly plasticized and loses dimensional stability (see inset in Figure 4) during the assay at $21^{\circ} \mathrm{C}$. However, the PET2 packaging film sample with higher crystallinity and melting point did show a better performance in permeability to limonene (permeability of $8 \times 10^{-13} \mathrm{~g} / \mathrm{m}^{2} \mathrm{~s} \mathrm{~Pa}$ ) than PHBV (Figure 4).

In Table 1, the diffusion coefficient for limonene seems higher in PET and PCL than in PHBV. Nevertheless, permeability to toluene and ethanol is clearly higher in PHBV than in PET, which indicates that the solvent resistance of the biopolymer is lower than that obtained with PET. The large difference in the chemical resistance between the two materials was found to be related to partial dissolution over time of the biopolymer in these two solvents, suggested by weight loss and FT-IR measurements (results not shown). Further research in this area is being carried out at the moment to better understand the behavior of these biopolymers in these and other aroma and solvent components.

Figure 5 shows the comparative permeability data to oxygen for a number of oil-based materials, biopolymers, and nanocomposites (4\% addition of NanoBioMatters proprietary clays for food contact applications). From the permeability results, it is seen that the biodegradable materials have higher oxygen permeability compared to PET at $21^{\circ} \mathrm{C}$ at $40 \% \mathrm{RH}$ (test conditions used unless otherwise stated). 


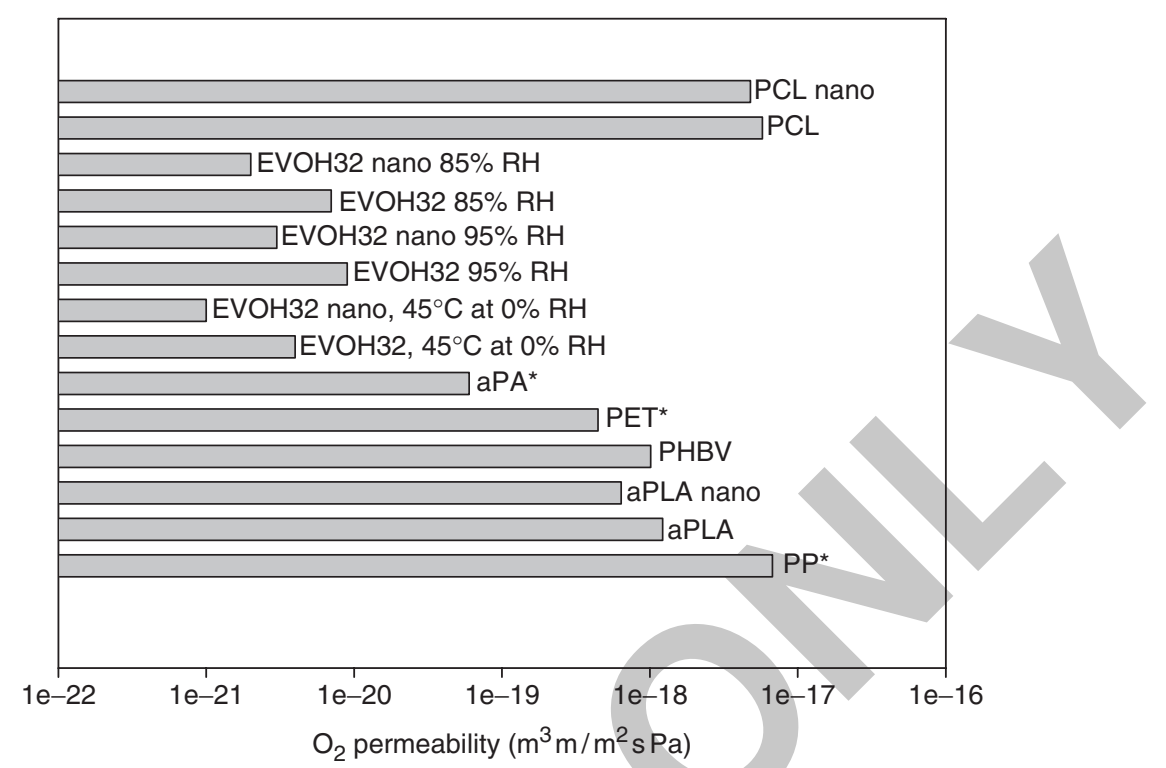

Figure 5. Oxygen permeability of biomaterials, melt-mixed nanobiocomposites, and other reference materials [3]. Values for materials with * were gathered from [10].

However, the nanobiocomposites all have lower permeability to the test gas than the neat biopolymer. Although barrier improvements are clear in the nanobiocomposites (ca. 50\% permeability reduction for aPLA), the barrier enhancement in these materials is lower than that previously measured [3] in EVOH nanocomposites ( $>75 \%$ reduction at $0 \% \mathrm{RH}$ ), which indicates that there may be further improvement in the modification route and/or morphology of the nanobiocomposites to increase performance. A new range of tailor-made nanoadditives for biopolymers is being tested at the moment to enhance further the overall performance of the nanobiocomposites.

\section{ACKNOWLEDGMENTS}

The work performed at the synchrotron facility in Hamburg (HASYLAB, Germany) was supported by the IHP-Contract HPRI-CT1999-00040/2001-00140 of the European Commission, and the authors would like to acknowledge Dr S. S. Funari and $\mathrm{Mr}$ M. Dommach (HASYLAB) for experimental support. The authors would also like to acknowledge the Spanish MEC (Project MAT2003-08480-C3), the SUSTAINPACK FP6 EU project for financial support, 
and Nanobiomatters S.L. (Spain) for supplying samples and financial support.

\section{REFERENCES}

1. Weber, C.J., Haugaard, V., Festersen, R. and Bertelsen, G. (2002). Food Additives and Contaminants, 19: 172.

2. Petersen, K., Nielsen, P.V. and Olsen, M.B. (2001). Starch, 53: 356.

3. Lagaron, J.M., Cabedo, L., Feijoo, J.L., Gavara, R. and Gimenez, E. (2005). Improving Packaged Food Quality and Safety: (II) Nanocomposites, Food Additives and Contaminants, 22(10): 994.

4. Cava, D., Catala, R., Gavara, R. and Lagaron, J.M. (2005). Testing Limonene Diffusion Through Food Contact Polyethylene by FT-IR Spectroscopy: Film Thickness, Permeant Concentration and Outer Medium Effects, Polymer Testing, 24: 483.

5. Lagaron, J.M., Powell, A.K. and Bonner, J.G. (2001). Permeation of Water, Methanol, Fuel and Alcohol-containing Fuels in High-barrier EthyleneVinyl Alcohol Copolymer, Polymer Testing, 20: 569.

6. López-Rubio, A., Lagaron, J.M., Gimenez, E., Cava, D., Hernández-Muñoz, P., Yamamoto, T. and Gavara, R. (2003). On the Morphological Alterations Induced by Temperature and Humidity in Ethylene-vinyl Alcohol Copolymers, Macromolecules, 36: 9467-9476.

7. Tsai, B.C. and Wachtel, J.A. (1990). Barrier Polymers and Structures, p. 192, American Chemical Society: Washington, DC.

8. Auras, R., Harte, B. and Selke, S. (2004). Effect of Water on the Oxygen Barrier Properties of PET and Polylactide Films, J. Appl. Polym. Sci., 92: 1790.

9. Auras, R., Harte, B. and Selke, S. (2006). Sorption of Ethyl Acetate and D-limonene in Polylactide Polymers, J. Sci. Food Agriculture, 86: 648.

10. Permeability and Other Film Properties of Plastics. (1995). PDL Handbook Series, Plastics Design Library, Norwich, NY.

\section{BIOGRAPHIES}

\section{David Cava}

David Cava is a PhD student at the Institute of Agrochemistry and Food Technology (IATA), Spanish Superior Council for Scientific Research (CSIC). He graduated in Agricultural Engineering from the Polytechnic University of Valencia, Spain. 


\section{Enrique Giménez}

Enrique Giménez is a Professor of Materials Science at the University Jaume I, Castellon. He graduated in Industrial Engineering from the Polytechnic University of Valencia and received a PhD at the University of Castellon, Spain. He is a Scientific Advisor at NanoBioMatters Ltd., Paterna, Spain.

\section{Rafael Gavara}

Rafael Gavara is a Research Scientist and Project Leader in FoodPackaging Interactions at IATA, CSIC). He graduated in Chemistry and earned a PhD Chemistry at the University of Valencia, Spain.

\section{Jose M. Lagaron}

Jose M. Lagaron is a Senior Research Scientist and Project-Leader in Novel Materials and Nanotechnology at IATA, CSIC. He graduated in Chemistry and obtained his $\mathrm{PhD}$ in Polymer Physics at the University of Valladolid, Valladolid, Spain. He is a Scientific Advisor at NanoBioMatters Ltd. 